\title{
Characterising double frequent users in an emergency department
}

\author{
Annelie Raidla ${ }^{1}$, Katrin Dárro ${ }^{1}$, Tobias Carlson ${ }^{1}$, Eric Carlström¹,2,3 \\ ${ }^{1}$ Emergency Department at Östra Hospital, Sahlgrenska University Hospital, Gothenburg, Sweden \\ ${ }^{2}$ Institute of Health and Care Sciences, Sahlgrenska Academy, University of Gothenburg, Sweden \\ ${ }^{3}$ University College of Southeast Norway, Vestfold, Norway
}

Received: February 11, 2018

DOI: $10.5430 /$ jha.v7n3p35
Accepted: April 15, 2018

Online Published: April 23, 2018

\begin{abstract}
Visits by frequent users (FUs) has been suggested as one reason for crowding in emergency departments (EDs). In this article, we identified the characteristics of double frequent users (DFUs), $\geq 8$ visits during 12 months in an ED during a period of six years, in one ED in Western Sweden. The primary outcome was to characterise DFUs and find common reasons for repeatedly visiting the ED. We conducted a retrospective cohort analysis on register data covering six years of all visits. The DFUs share of all visitors to the ED was not more than $0.03 \%$ (144 individuals), but their share of visits was $2.4 \%$ (1,017 visits/year). Chest pain and abdominal pain were the most common complaints. A typical DFU is male, around 50-year-old, unemployed, non-immigrant, suffering from alcohol abuse and/or mental health conditions. The results point to the need for changing strategies in ED services towards DFUs suffering from alcohol abuse and/or mental health conditions. The ED prioritises the severely ill but lacks resources and continuity for handling chronic diseases and follow-up routines.
\end{abstract}

Key Words: Emergency department, Frequent users, Sweden

\section{INTRODUCTION}

For the past few decades, overcrowding at emergency departments (EDs) has been reported as an increasingly worrying occurrence. ${ }^{[1,2]}$ It has been associated with risk of in-hospital mortality, longer waiting times prior to treatment for severely ill patients and higher probability of leaving the ED against medical advice or without being seen ${ }^{[3]}$ Frequent users (FUs usually $\geq 4$ visits during 12 months) have been suggested as an important reason for ED crowding. ${ }^{[4]}$ In this article, we identified the characteristics of double frequent users (DFUs), $\geq 8$ visits during 12 months and at least 25 visits to ED during a period of six years. The primary outcome was to understanding reasons for frequent visits to the ED.
Such understanding can be crucial for developing proper alternatives of care.

\subsection{Australia and US}

International research points out general and contextual related characteristics of FUs. In an Australian study by Quilty et al. in 2016, FUs in ED facilities had twice as much unstable living arrangements than the average ED patient. They were often homeless (14 times more than average), and alcohol abuse was a contributing factor in more than half of the cases. FUs displayed higher mortality (7.3\%) than the average ED patient (2.9\%). ${ }^{[5]}$ In a study from US by Ondler, Hedge \& Carlson in 2014, FUs also proved to suffer from

\footnotetext{
* Correspondence: Eric Carlström; Email: eric.carlstrom@gu.se; Address: Institute of Health and Care Sciences, Sahlgrenska Academy, University of Gothenburg, 41346 Gothenburg, Sweden.
} 
unstable living arrangements. They were more often unemployed, lacked private insurance and suffered from mental health conditions. They also used more tobacco and had more intolerance to medications than the average ED patient. ${ }^{[6]}$ Another US study showed higher frequencies of mental health diseases, abuse of alcohol and drugs among FUs compared to the average ED patient. The results showed that $77.3 \%$ of frequent visitors, i.e. $>19$ visits during 12 months, suffered from either mental health disturbances or alcohol and drug abuse compared to $6.9 \%$ among the average ED patients. ${ }^{[7]}$ In healthcare based on fee for service such as in the US, patients involved in social healthcare programmes are overrepresented in the EDs. Vinton et al. showed that $12 \%$ of Medicaid enrolees who visited EDs accounted for $38 \%$ of all ED visits. The most common ED diagnoses in the study by Vinton et al., within the group, were abdominal pain and alcohol-related disorders. The group was also more likely to be homeless. ${ }^{[8]}$

\subsection{Europe}

A few studies on characteristics of FUs have been performed in Europe. In a study from Netherlands, including FUs aged 18 years and older, FUs represented $2 \%$ of all patients visiting EDs, and $8 \%$ of all visits to the ED were made by FUs during 2009-2013. The FUs were less often transported by ambulance and received lower priority than the average ED patients. The most common complaints were related to the digestive system (19\%); the second most common complaint was general issues, such as fever $(18 \%)$ followed by respiratory $(10 \%)$ or cardiovascular problem $(10 \%) .{ }^{[9]}$ A Swiss study by Althaus et al. in 2013, on patients visiting the ED at least 12 times or more within a year, revealed that one-third attempted suicide during a one year study period. As much as $82.6 \%$ of the studied patients were unemployed, $73.9 \%$ were socially isolated and $60.9 \%$ suffered from mental health disorder and/or use of drugs. They were considered a highly vulnerable population, poor in health, and exhibited several risk factors for having even poorer health. ${ }^{[10]}$ Another Swiss study showed that FUs were younger, more often immigrants from low/middle income countries, unemployed, had more somatic and psychiatric comorbidities than the average EDpatient. They were more often tobacco users and had more primary care visits than the average ED visitor. ${ }^{[1]}$ Turning to Sweden, from where the data for this article are collected, to the best of our knowledge, no studies have addressed specific characteristics of frequent ED visitors. In a study by Bergh and Marklund in 2003, the characteristics of FUs in primary healthcare were studied. FUs constituted $3.3 \%$ of the population but accounted for $25 \%$ of all visits to general practitioners. They showed morbidity with a preponderance of infections at young age, musculoskeletal problems in mid- dle age, and among the oldest, circulatory, endocrine and musculoskeletal diseases. Single middle-aged women, with unstable living arrangements, were over represented. ${ }^{[12]}$

\section{METHODS}

The studied ED was situated in a hospital in Gothenburg in western Sweden. The ED was part of the Sahlgrenska University Hospital, distributed in three main hospital complexes in different districts, with one ED each. Each of the EDs received approximately one-third of the annual 150,000 ED visits in the town. The studied ED was typical, i.e. treating diseases and injuries from 16 years of age, excluding orthopaedic and psychiatric diseases. The studied ED received 50,721 visits during 2016, which was an increase of $9.2 \%$ from the year before. The trend of more visits had been apparent during the last few decades. The ED served the part of the county characterised by the weakest socioeconomic status and highest degree of immigrants.

\subsection{Sample}

The study was based on six years register data of all visitors to the studied ED, from 2010 to 2015 . DFUs were identified and data was selected from medical journals. The data was aggregated and analysed in the study.

\subsection{Analysis}

We conducted a retrospective cohort analysis of the sample. The primary focus was to characterise DFUs and find most common reasons for visiting the ED. Secondary focus included determining share of visits, age and time spent in the ED. The statistics were descriptive including shares in per cent, central tendency and dispersion. The average length of stay was used as a proxy in the calculation. The length of stay was defined as the time spent from admission to discharge from the ED or admission to a ward. When means were compared, a statistical significance was recognised at $p<.05 .{ }^{[13]}$

\section{RESULTS}

The ED reported 43,212 visits per year, on average. The average age of the patients was 52 years $(S D=9.5)$, with $51 \%$ women and $49 \%$ men. The average time spent by the patient in the ED was 3.82 hours $(S D=0.39)$.

\subsection{Share of visits}

As many as 6,136 (14.2\%) visits per year were made by 1,110 FUs and 1,017 visits were made by 144 DFUs. The DFUs share of all visitors to the ED was not more than $0.03 \%$, but their share of visits was $2.4 \%$ and they spent more time at the ED than average. A number of 87 of them were in the working age population, but only $18 \%$ were employed. Not 
more than $17 \%$ of the DFUs were immigrants. This should In 2015, DFUs had an average age of 58 years $(S D=19.1)$, be compared to the share of immigrants in the main catch- $56 \%$ men and $44 \%$ women (see Table 1). ment areas of the studied ED, i.e. $64.3 \%$ of the population.

Table 1. Visits, individuals, age, gender and time spent, on average, at the ED during one year based on data from the six-year study period

\begin{tabular}{|c|c|c|c|c|c|c|}
\hline & Visits & Individuals & Age $(S D)$ & Women & Men & Time sp. $(S D)$ \\
\hline All & 43,212 & 33,292 & $52(9.5)$ & $51 \%$ & $49 \%$ & $3.82 \mathrm{~h}(0.39)$ \\
\hline FUs $(\geq 4)$ & 6,136 & 1,110 & $58(14.0)$ & $51 \%$ & $49 \%$ & $4.03 \mathrm{~h}(0.15)$ \\
\hline DFUs $(\geq 8)$ & 1,017 & 144 & $58(19.1)$ & $44 \%$ & $56 \%$ & $4.09 \mathrm{~h}(1.88)$ \\
\hline
\end{tabular}

\subsection{Reasons to visit the ED}

The most common reason for DFUs visiting the ED was chest pain $(22 \%)$. The next most common reason was abdominal pain $(21 \%)$. These were followed by Dyspnea (14\%). Out of the 144 DFUs, $74 \%$ suffered from drug or alcohol abuse or/and psychiatric comorbidities (DAA/PC), and 51\% suffered from multiple comorbidity, i.e. presence of one or more additional diseases or disorders co-occurring with a primary disorder.

\subsection{Distribution of visits made by DAA/PC and multi co- morbidity DFUs}

The patients suffering from drug or alcohol abuse or/and psychiatric comorbidities was younger, i.e. 50.9-year-old $(S D=$ 17.97), than the multiple comorbidity patient, i.e. 70.6-yearold $(S D=13.97)$. The number of hours DFUs spent at the ED annually was 5,085 hours; DAA/PC patient was in majority, 4,018 hours; and the multi comorbidity patient spent 215 hours at the ED. The number of DAA/PC patients visiting the ED daily was, on average, 2.2 and the most frequent user visited the ED 209 times during the six-year period (i.e. 35 visits/year).

Even though the visits to the ED increased during the sixyear period, on average $7 \%$ every year, the share of visits by FUs and DFUs were in accordance with the total number of visits (6\% per year). This indicated that the FUs and DFUs share of the ED population was stable over the years, on average $14.2 \%$ for FUs and $2.4 \%$ for DFUs. The turn-over rate of the average DFU were 4.1 years and $17.7 \%$ of the DFUs were replaced every year.

The DFUs' reasons for visiting the ED was stable during the six-year study period. Chest pain, abdominal pain and dyspnea were identified as the most common reasons from 2010 to 2015. When looking at the distribution of DAA/PC and multiple comorbidity of all DFUs, the DAA/PCC was still dominating. In contrast, the share of multiple comorbidity showed a tendency to increase (from $45 \%$ in 2010 to $56 \%$ in 2015) (see Figure 1).



Figure 1. Share of DFUs' reasons for visiting the ED and the share of DAA/PC and Multi Comorbidity during the six-year period 2010-2015

\section{Discussion}

In this study, we identified the characteristics of DFUs. Patients suffering from Drug or Alcohol Abuse or/and Psychiatric Comorbidities (DAA/PCs) dominated the DFUs (74\%). They accounted for $79 \%$ of all DFUs' visits at the ED. The majority were men (56\%), and only $18 \%$ of the DFUs in working age were employed. In contrast to the study by Bodenmann et al. in 2015, we found relatively few immigrants (17\%) in the DFU group even though the proportion of immigrants in the catchment area of the hospital was higher. ${ }^{[11]}$

Even though they visited the ED frequently, the DFUs was part of a relatively small cohort (144 individuals) and therefore possibly well-known by the staff. At an ED having 50,000 visitors per year, almost three daily visits were made by DFUs; furthermore, they stayed longer at the ED than other patients.

\subsection{A typical DFU}

Based on the results of this study, a typical DFU is male, around 50-year-old, unemployed, non-immigrant, suffering from alcohol abuse and/or mental health conditions and complaining of chest or abdominal pain. The DAA/PCs were, on average, 20 years younger than the DFU suffering from 
multi comorbidity.

\subsection{The financing system matters}

These results are in contrast to LaCalle and Rabin's study who found FUs to be a heterogeneous group. They found the age to be bimodal, with peaks in groups aged 25, 44 and 65 years. The patients were regarded as heavy users of different levels of the healthcare system, however, with limited access because of varying public insurance. ${ }^{[14]}$ The difference between financing systems, e.g. US-insurance system versus the European Beveridge model, can limit the comparability when studying FUs from an international perspective. A study from Ireland, which has a Beveridge model, as in Sweden, defines, in agreement with this study, a frequent user to be a man, around 55-year-old suffering from DAA/PC They were users of several public health services, community welfare services, addiction counselling and psychiatric services. ${ }^{[15]}$

\subsection{Insufficient service}

The main goal of EDs is to assess acute conditions, decide about hospitalised therapy or other levels of care. ${ }^{[16]}$ To the best of our knowledge few other studies have showed DFUs increasing at the same rate as the total population of visitors to the ED. Because the number of visitors to the studied ED was constantly increasing every year, the DFUs were provided an increasing amount of ED services. The repetitive character and stability in distribution of the complaints from DAA/PC may indicate the service provided by the ED to be insufficient.

\subsection{A challenge to improve ED services}

The results from this study point to a need for change in strategies in ED services towards DAA/PCs. The ED is well equipped to handle emergency care of physical injuries and diseases but is challenged by patients suffering from combinations of physical, psychological and social factors. It also challenge continuity to handle chronic diseases and followup routines. For the DFUs repeatedly visiting the ED, the service appears as poor. The main question is how to direct the DFUs towards primary care, rather than the ED. The answer can be found in the degree of accessibility. The primary care in Sweden is often closed in the evenings, weekends and during the evenings. ${ }^{[17]}$

\subsection{Overlap and workflow}

One challenge is to provide a smooth overlap in care between different providers. ${ }^{[18]}$ Workflow improvements have proven to be efficient if they are implemented simultaneously. ${ }^{[19]}$
Gayathri and Klein studied case management as one way to reduce ED visits by FUs and found a reduction of ED use. Other strategies used to affect ED utilisation by FUs were individualised care plans, patient education, primary care partnerships and managed care level interventions. Such results seemed to be promising and allow for interventions aimed at providing appropriate service to DFUs, thus, alleviating some of the overcrowding concerns at EDs. ${ }^{[20]}$

\subsection{Limitations}

The definition of FUs and consequently DFUs vary in the literature. To the best of our knowledge, the most common definition of a FU is 4 or more visits during a 12-month period. In order to support comparability between studies, a shared definition would benefit future research. The study was limited to one ED in western Sweden. In order to verify the results, it is necessary to perform wider studies. Even if the data show statistical significance, the generalisability to other national contexts can be questioned because of differences in financial, payment, organisational and cultural structures.

\section{Conclusions}

In this study, we identified the characteristics of DFUs in one ED in Western Sweden. The DAA/PCCs dominated the group of DFUs (74\%), out of which $79 \%$ of all DFUs visited the ED. Based on the results of this study, a typical DAA/PCC is male, around 50-year-old, unemployed, non-immigrant, suffering from alcohol abuse and/or mental health conditions. The results point to the need for developing strategies towards DAA/PC DFUs. The target group has to be successfully identified and separated from emergency cases in order to provide proper service.

\section{ACKNOWLedgements}

This is an investigator-initiated study. Sahlgrenska University Hospital, Area 2 has funded the work of this paper. The funder played no part in the design of the study or in the analysis of the results. The investigators thank the staff of the Östra hospital to data entry and Alf Karlsson to data processing during the study.

\section{ETHICS APPROVAL}

Ethical approval was obtained from the regional ethical board in Western Sweden, registration number 2017/625.

\section{CONFLICTS OF INTEREST DISCLOSURE}

The authors declare they have no conflicts of interest. 


\section{REFERENCES}

[1] Carter E. The Relationship Between Emergency Department Crowding and Patient Outcomes: A Systematic Review. J Nurs Scholar. 2014; 46(2): 106-15. PMid: 24354886. https://doi.org/10.1 $111 /$ jnu. 12055

[2] Kellerman AL. Crisis in the emergency department. New Eng J Med. 2006; 355: 1300-03. PMid: 17005946. https ://doi.org/10.105 6/NEJMp068194

[3] Bernstein SL, Aronsky D, Duseja R, et al. The Effect of Emergency Department Crowding on Clinically Oriented Outcomes. Acad Emerg Med. 2009; 16(1): 1-10. PMid: 19007346. https: //doi.org/10.1111/j.1553-2712.2008.00295.x

[4] Edgren G, Anderson J, Dolk A, et al. A case management intervention targeted to reduce healthcare consumption for frequent Emergency Department visitors: results from an adaptive randomized trial. Eur J Emerg Med. 2015; 23(5): 344-50. PMid: 25969342. https://doi.org/10.1097/MEJ .0000000000000280

[5] Quilty S, Shannon G, Yao S, et al. Factors contributing to frequent attendance to the emergency department of a remote Northern Territory Hospital. Med J Aus. 2016; 204(3): 1-7. https: //doi.org/10.5694/mja15.00648

[6] Ondler C, Hedge GG, Carlson JN. Resource utilization and health care charges associated with the most frequent ED users. Am J Emerg Med. 2014; 32(10): 1215-19. PMid: 25154348. https: //doi.org/10.1016/j.ajem.2014.07.013

[7] Liu SW, Nagurney JT, Chang Y, et al. Frequent ED users: are most visits for mental health, alcohol, and drug-related complaints? Am J Emerg Med. 2013; 31(10): 1512-15. PMid: 24035051. https: //doi.org/10.1016/j.ajem.2013.08.006

[8] Capp R, Rosenthal MS, Mayur MD, et al. Characteristics of Medicaid enrollees with frequent ED use. Am J Emerg Med. 2013; 31(9): 1333-37. PMid: 23850143. https ://doi.org/10.1016/j.ajem .2013 .05 .050

[9] Bertoli-Avelli AM, Haagsma JA, Van Tiel S, et al. Frequent users of the emergency department services in the largest academic hospital in the Netherlands: a five year report. Eur J Emerg Med. 2015; 24(2): 130-35. PMid: 26287805. https://doi.org/10.1097/MEJ.00 00000000000314

[10] Althaus F, Stucki S, Gyiot S, et al. Characteristics of highly frequent users of a Swiss academic emergency department: a retrospective consecutive case series. Eur J Emerg Med. 2013; 30(6):
413-19. PMid: 23337095. https ://doi.org/10.1097/MEJ.0b $013 \mathrm{e} 32835 \mathrm{e} 078 \mathrm{e}$

[11] Bodenmann P, Baggio S, Iglesias K, et al. Characterizing the vulnerability of frequent emergency department users by applying a conceptual framework: a controlled, crossectional study. Int J Equ Health. 2015; 14: 146-56. PMid: 26645272. https ://doi .org/10 $.1186 / \mathrm{s} 12939-015-0277-5$

[12] Bergh H, Marklund B. Characteristics of frequent attenders in different age and sex groups in primary health care. Scand J Prim Health Care. 2003; 21(3): 171-77. PMid: 14531510. https://doi.org/ 10.1080/02813430310001149

[13] Altman DG. Practical statistics for medical research. New York: Chapman and Hall; 1991. 181-3 p.

[14] LaCalle E, Rabin E. Frequent Users of Emergency Departments; The Myths, the Data, and the Policy Implications. Ann Emerg Med. 2009; 56(1): 42-8. PMid: 20346540. https ://doi.org/10.1016/j.an nemergmed.2010.01.032

[15] Byrne M, Murphy AW, Plunkett PK, et al. Frequent Attenders to an Emergency Department: A Study of Primary Health Care Use, Medical Profile, and Psychosocial Characteristics. Ann Emerg Med 2003; 41(3): 309-18. PMid: 12605196. https://doi.org/10.1 067/mem . 2003.68

[16] Kumar GS, Klein R. Effectiveness of case management strategies in reducing emergency department visits in frequent user patient populations: A systematic review. J Emerg Med. 2013; 44(3): $717-$ 29. PMid: 23200765. https://doi.org/10.1016/j.jemermed .2012 .08 .035

[17] Carlström E. Change management in health-care. Lund: Studentlitteratur; 2013.

[18] Truong M, Meckler G, Doan QH. Emergency Department Return Visits Within a Large Geographical Area. J Emerg Med. 2017; 52(6): 801-7. PMid: 28228344. https ://doi .org/10.1016/j.jemerm ed. 2017.01 .009

[19] Notouzzadeh S, Garber J, Longacre M, et al. A Modular Simulation Study to Improve Patient Flow to Inpatient Units in the Emergency Department. Journal of Hospital Administration. 2014; 3(6): 205-215. https://doi.org/10.5430/jha.v3n6p205

[20] Gayathri SK, Klein R. Effectiveness of Case Management strategies in reducing Emergency Department visits in Frequent user patient populations: A systematic review. J Emerg Med. 2014; 44(3): 717 29. 